\title{
Caseinomacropeptide Self-Association is Dependent on Whether the Peptide is Free or Restricted in $\kappa$-Casein
}

\author{
T. L. Mikkelsen, ${ }^{1}$ H. Frøkiær, ${ }^{1}$ C. Topp, ${ }^{1}$ F. Bonomi, ${ }^{2}$ S. lametti, ${ }^{2}$ G. Picariello, ${ }^{3}$ \\ P. Ferranti, ${ }^{4}$ and V. Barkholt ${ }^{1}$ \\ ${ }^{1}$ Biochemistry and Nutrition group, Biocentrum-DTU, DK-2800 Lyngby, Denmark \\ ${ }^{2}$ DISMA, Sezione di Biochimica, University of Milan, Milan I-20133, Italy \\ ${ }^{3}$ ISA-CNR, Avellino I-83100, Italy \\ ${ }^{4}$ DSA, University of Naples "Federico II", Portici I-80055, Italy
}

\begin{abstract}
There is a general agreement that the experimentally determined molecular weight (MW) of caseinomacropeptide (CMP) is greater than the theoretical MW. Some studies suggest that this is due to a $\mathrm{pH}$-dependent aggregation of monomeric CMP. How this aggregation is influenced by $\mathrm{pH}$ is not understood. This study was carried out to study the nature of CMP aggregates and to clarify which conditions affect aggregation of CMP. The apparent MW of CMP at different $\mathrm{pH}$ values was determined using size-exclusion chromatography. Caseinomacropeptide was further characterized by immunochemical analysis, sodium dodecyl sulfate-PAGE, Nterminal sequencing, and mass spectrometry. The hydrophobicity of CMP was studied by means of 1-anilinonaphthalene-8-sulfonic acid binding experiments. Four CMP products prepared by different methods were studied: CMP produced by enzymatic (chymosin or pep$\sin$ ) hydrolysis of $\kappa$-casein (CN), and 2 commercial CMP products. Both commercial products and CMP resulting from chymosin-hydrolysis of $\kappa$-CN (at pH 6.6) had elution volumes with a MW corresponding to $35 \mathrm{kDA}$ at $\mathrm{pH} 8.0$ and 3.4. Caseinomacropeptide prepared from pepsin-hydrolysis of $\kappa$-CN (at $\mathrm{pH} 2.5$ ) eluted as multiple peaks with apparent MW of 35,18 , and $9 \mathrm{kDa}$, again independently of $\mathrm{pH}$. Hydrolysis of $\kappa$-CN with chymosin or pepsin at different $\mathrm{pH}$ values $(\mathrm{pH} 2.5,3.4$, and 6.6) produced differently sized aggregates of CMP, largely depending on the $\mathrm{pH}$ of the hydrolysis. These results indicate that, whereas CMP molecules are irreversibly associated, CMP in $\kappa$-CN may associate reversibly in a $\mathrm{pH}$-dependent manner. We suggest that interactions between para- $\kappa$-CN parts of the $\kappa$-CN molecules may be a requisite for the $\mathrm{pH}$-dependent dissociation/association.
\end{abstract}

Received February 3, 2005.

Accepted July 22, 2005.

Corresponding author: Vibeke Barkholt; e-mail: vb@biocentrum. dtu.dk.
(Key words: caseinomacropeptide, molecular weight, aggregation, $\kappa$-casein)

Abbreviation key: ANS = 1-anilinonaphthalene-8sulfonic acid, $\mathbf{C M P}=$ caseinomacropeptide, $\mathbf{M S}=$ mass spectrometry, $\mathbf{M W}=$ molecular weight, $\mathbf{S E C}=$ sizeexclusion chromatography.

\section{INTRODUCTION}

Caseinomacropeptide (CMP) is released after specific cleavage of $\kappa$-CN by chymosin (Farrell et al., 2004) and pepsin (Delfour et al., 1965) at the Phe105-Met106 peptide bond. Caseinomacropeptide comprises the 64 amino acids in the hydrophilic C-terminal portion of $\kappa$ $\mathrm{CN}$, and contains all the posttranslational modifications (glycosylation and phosphorylation) present in $\kappa$ $\mathrm{CN}$ that contribute to its marked heterogeneity. An increasing number of studies show that CMP may exert important biological activities (Abd El-Salam et al., 1996), and this explains the growing interest in CMP as an ingredient in dietetic food and pharmaceutical products. Much attention has been given to developing techniques for the isolation and purification of CMP, but a better understanding of the physicochemical properties of CMP is important to optimize isolation methods.

The sequence-derived molecular weight of CMP (genetic variant A) is $6.707 \mathrm{kDa}$ (Jolles et al., 1972); however, most reports indicate much higher values for experimentally measured molecular weight (MW). About $40 \%$ of CMP is not glycosylated (Vreeman et al., 1986), and it is therefore not conceivable that the attached carbohydrate chains can account for the higher MW. Previous studies suggest that CMP forms aggregates, and that aggregation occurs at $\mathrm{pH}$ values above 4.5. Accordingly, methods for industrial scale preparation by ultrafiltration of CMP that rely on this phenomenon have been developed (Tanimoto et al., 1992; Holst and Chatterton, 2002). This apparent $\mathrm{pH}$-dependent aggregation, however, is still debated (Brody, 2000), and in some studies, $\mathrm{pH}$-dependent changes in the MW of CMP 
have not been observed (Minkiewicz et al., 1996; Nakano and Ozimek, 1998). In fact, some studies argue that the larger apparent MW is not caused by aggregation but can be attributed to a large hydrodynamic volume (Minkiewicz et al., 1996; Wang and Lucey, 2003).

The aim of the present study was to investigate the nature of CMP concerning MW as well as to identify the conditions that may affect aggregation. We investigated the effect of $\mathrm{pH}$ on the apparent MW of CMP, as well as the conditions under which CMP forms aggregates. A better knowledge of the physicochemical properties of CMP is essential to optimize production and isolation methods for CMP and provide a basis for understanding the biological activities of CMP.

Four CMP products prepared by different methods were studied: 2 commercial products (Sigma and Arla), and 2 CMP products produced in our laboratory by enzymatic hydrolysis of $\kappa$-CN with chymosin (at $\mathrm{pH}$ 6.6) or pepsin (at $\mathrm{pH} 2.5$ ). According to the manufacturer, CMP from Sigma (Sigma Chemical Co., St. Louis, MO) was produced by precipitation of rennin-treated whole casein with $5 \%$ (wt/vol) TCA. The product commercialized by Arla (Arla Foods Amba, Viby, Denmark) was isolated from sweet whey by several ultrafiltration steps (Holst and Chatterton, 2002).

\section{MATERIALS AND METHODS}

\section{Protein Material}

Recombinant chymosin (CHY-MAX Plus, 205 international milk clotting units $/ \mathrm{mL}, 0.92 \mathrm{mg} / \mathrm{mL}$, EC 3.4.23.4) was a gift from Chr. Hansen, Hørsholm, Denmark; pepsin (EC 3.4.23.1), CMP, and $\kappa$-casein were from Sigma; and CMP (CCMP-10) was from Arla Foods Amba. The MW standards used for size-exclusion chromatography (SEC) were BSA (Sigma), ovalbumin (Sigma), carbonic anhydrase (Sigma), $\alpha$-chymotrypsinogen A (Sigma), bovine pancreatic trypsin inhibitor (D-68298, Boehringer Mannheim, Mannheim, Germany). The set of MW markers used in SDS-PAGE was Mark 12 (LC-5677, Invitrogen, San Diego, CA). Water was drawn from a Milli-Q system equipped with an Organex cartridge (Millipore, Bedford, MA).

\section{Chymosin Hydrolysis of $\kappa$-CN}

A $10 \mathrm{mg} / \mathrm{mL}$ solution of $\kappa$-CN was prepared in $10 \mathrm{~m} M$ sodium phosphate buffer ( $\mathrm{pH}$ 6.6) to which chymosin [0.02 international milk clotting units/mL; 1:1000 (wt/ wt)] was added. A control containing no chymosin (designated chymosin-control) was prepared simultaneously. After $1 \mathrm{~h}$ at $37^{\circ} \mathrm{C}$, the $\mathrm{pH}$ was adjusted to 9.0 with $1.0 \mathrm{M} \mathrm{NaOH}$. After centrifugation (20 min at $12,000 \times$ $g$, room temperature), the precipitate was discarded, and the protein concentration in the supernatant was determined by amino acid analysis (Barkholt and Jensen, 1989). The supernatant was stored at $-20^{\circ} \mathrm{C}$ until analysis. For chymosin hydrolysis at $\mathrm{pH} 2.5$ and 3.4, the $\mathrm{pH}$ of a $10 \mathrm{mg} / \mathrm{mL}$ solution of $\kappa$-CN prepared in 10 $\mathrm{mM} \mathrm{NH} \mathrm{NHCO}_{3}$ was adjusted to the respective $\mathrm{pH}$ with $1 M \mathrm{HCl}$ before hydrolysis, which was performed as described above.

\section{Pepsin Hydrolysis of $\kappa-\mathrm{CN}$}

A $10 \mathrm{mg} / \mathrm{mL}$ solution of $\kappa$-CN was prepared in $10 \mathrm{~m} M$ $\mathrm{NH}_{4} \mathrm{HCO}_{3}$. The $\mathrm{pH}$ was adjusted to $\mathrm{pH} 2.5$ with $6 \mathrm{M}$ $\mathrm{HCl}$, and pepsin (1:1000, wt/wt) was added. A control containing no pepsin (designated pepsin-control) was prepared simultaneously. After $1 \mathrm{~h}$ at $37^{\circ} \mathrm{C}$, the $\mathrm{pH}$ was adjusted to 7.4 with $1 M \mathrm{NH}_{4} \mathrm{HCO}_{3}$, and the sample was centrifuged (20 min at $12,000 \times g$, room temperature). The precipitate was discarded and the protein concentration in the supernatant was determined by amino acid analysis (Barkholt and Jensen, 1989). The supernatant was stored at $-20^{\circ} \mathrm{C}$ until analysis. For pepsin-hydrolysis at $\mathrm{pH} 3.4$ and 6.6 , the $\mathrm{pH}$ of a $10 \mathrm{mg} /$ $\mathrm{mL}$ solution of $\kappa$-CN prepared in $10 \mathrm{mM} \mathrm{NH}_{4} \mathrm{HCO}_{3}$ was adjusted to the respective $\mathrm{pH}$ with $1 \mathrm{M} \mathrm{HCl}$ before hydrolysis, which was performed as described above.

\section{Size-Exclusion Chromatography}

Size-exclusion chromatography was performed on a Superdex 75 PC 3.2/30 column mounted on a SMART system (Pharmacia Biotech AB, Uppsala, Sweden). Chromatography was carried out at room temperature at $\mathrm{pH} 8.0\left(150 \mathrm{mM} \mathrm{NH}_{4} \mathrm{HCO}_{3}\right)$ or at $\mathrm{pH} 3.4(25 \mathrm{~m} M$ $\mathrm{CH}_{3} \mathrm{COOH}, 125 \mathrm{mM} \mathrm{NaCl}$ ), at a flow rate of $50 \mu \mathrm{L} / \mathrm{min}$. The run time for each experiment was $75 \mathrm{~min}$. Elution profiles were monitored at 280 and $220 \mathrm{~nm}$. Peaks containing CMP (that does not contain tryptophan or tyrosine) generally showed very little if any absorbance at $280 \mathrm{~nm}$. Standards used for column calibration were BSA (68 kDa), ovalbumin ( $43 \mathrm{kDa})$, carbonic anhydrase $(30 \mathrm{kDa}), \alpha$-chymotrypsinogen $\mathrm{A}(23 \mathrm{kDa})$, and bovine pancreatic trypsin inhibitor $(6.5 \mathrm{kDa})$. Fifteen microliters of the sample ( $1 \mathrm{mg}$ of protein $/ \mathrm{mL}$ ) was applied to the column. For runs performed at $\mathrm{pH}$ 3.4, all samples were adjusted to $\mathrm{pH} 3.4$ with $2.0 \mathrm{M}$ acetic acid and incubated for $2 \mathrm{~h}$ at room temperature before loading on the column. No prior incubation was carried out for runs at $\mathrm{pH}$ 8.0. Insoluble material in all samples was removed by quick centrifugation $(1 \mathrm{~min}$ at $12,000 \times \mathrm{g}$ ) before loading on the column.

To collect larger amounts of protein eluate for further analysis, preparative SEC was carried out at $\mathrm{pH} 3.4$ (5 $\mathrm{m} M \mathrm{CH}_{3} \mathrm{COOH}, 125 \mathrm{~m} M \mathrm{NaCl}$ ) on a Superdex 75 col- 
umn (Hiload 26/60, AP Biotech, Uppsala, Sweden) operating at a flow rate of $2 \mathrm{~mL} / \mathrm{min}$. Six milliliters of sample $(3 \mathrm{mg} / \mathrm{mL})$ was applied to the column, and 2 $\mathrm{mL}$ fractions were collected.

\section{ELISA}

Microtiter plates (Maxisorp, Nunc, Roskilde, Denmark) were coated overnight at $4^{\circ} \mathrm{C}$ with $0.5 \mu \mathrm{g} / \mathrm{mL}$ CMP (Sigma) in carbonate buffer ( $50 \mathrm{mM}$, pH 9.6). After washing, the CMP samples were added $(50 \mu \mathrm{g} / \mathrm{mL}, 50$ $\mu \mathrm{L}$ ) together with monoclonal anti-CMP antibody (50 $\mu \mathrm{g} / \mathrm{mL}, 50 \mu \mathrm{L}$ ) that was produced in our laboratory and demonstrated to bind specifically to $\kappa$-CN and CMP. Fractions collected from SEC were serially diluted in PBS containing $0.1 \%$ Triton $\mathrm{X}-100, \mathrm{pH}$ 7.4. The plates were incubated for $1 \mathrm{~h}$ at room temperature. After washing, plates were incubated for $1 \mathrm{~h}$ with horseradish peroxidase-conjugated rabbit antimouse antibody (DAKO A/S, Denmark; 1:1000 in PBS with $0.1 \%$ Triton $\mathrm{X}-100)$. Plates were developed by adding $100 \mu \mathrm{L} /$ well of substrate solution containing 3,3',5,5'-tetramethylbenzidine (Merck, Darmstadt, Germany) in hydrogen peroxide. The reaction was stopped after $10 \mathrm{~min}$ by adding $100 \mu \mathrm{L} /$ well of $2 M$ phosphoric acid. Optical density was measured at $450 \mathrm{~nm}$ with $630 \mathrm{~nm}$ as reference. Caseinomacropeptide from Arla was used as a standard for assessing the CMP concentration in each fraction.

\section{SDS-PAGE}

Sodium dodecyl sulfate-PAGE of CMP products was carried out using precast Tricine porosity gradient gels (10 to 20\% monomer, EC6625; Novex, Invitrogen, Groningen, The Netherlands). Samples were mixed 1:1 with sample buffer (0.1 $M$ Tris-base, $8 \%$ (wt/vol) SDS, $24 \%$ (vol/vol) glycerol, $0.025 \%$ (wt/vol) Coomassie, $0.04 M$ dithiothreitol; adjusted to $\mathrm{pH}$ 6.8), and boiled for $5 \mathrm{~min}$ (Schagger and von Jagow, 1987). Sample lanes were loaded with 10 to $20 \mu \mathrm{g}$ of protein, or with $2 \mu \mathrm{L}$ of a MW standard solution. Electrophoresis was carried out for $80 \mathrm{~min}$ at constant voltage $(125 \mathrm{~V})$. Gels were fixed and silver stained according to published procedures (Blum et al., 1987).

\section{Protein Sequencing}

Protein sequencing was carried out by automated $\alpha$ amino terminal Edman degradation in a Procise 494 sequenator according to the recommendations of the manufacturer (Applied Biosystems/Perkin Elmer, Foster City, CA). At least 3 residues were sequenced for each determination.

\section{Mass Spectrometry}

Before mass spectrometry (MS), samples previously lyophilized and redissolved in $0.1 \%$ (vol/vol) aqueous trifluoroacetic acid were purified from nonprotein components using Zip-Tip C18 prepacked microcolumns (Millipore) from which proteins were eluted in $40 \%$ (vol/ vol) aqueous acetonitrile containing $0.1 \%$ trifluoroacetic acid. Mass spectrometry analyses were performed using matrix-assisted laser desorption ionization time-offlight mass spectrometry (PerSeptive Biosystem, Framingham, MA) equipped with an $\mathrm{N}_{2}$-laser (337 nm, 3 ns pulse width, $20 \mathrm{~Hz}$ repetition rate). The instrument operated in positive linear ion mode with an accelerating voltage of $25 \mathrm{kV}$ and for each mass spectrum, 250 laser pulses were acquired. As matrix, both sinapinic acid (3,5 dimethoxy-4-hydroxy-cinnamic acid) and $\alpha$ cyano-4-hydroxy-cinnamic acid, prepared by dissolving $10 \mathrm{mg}$ of crystalline powder in $1 \mathrm{~mL}$ of aqueous $50 \%$ acetonitrile containing $0.1 \%$ trifluoroacetic acid were used. External mass calibration was performed by a separated analysis of a mixture of standard proteins. Mass spectra were elaborated using Data Explorer software furnished with the MS equipment.

\section{1-Anilinonaphthalene-8-Sulfonic Acid Binding Experiments}

Protein surface hydrophobicity in the various samples was assessed by spectrofluorimetric titration with 1-anilinonaphthalene-8-sulfonic acid (ANS), as reported elsewhere (Iametti et al., 1996, 1998). In short, emission fluorescence spectra were recorded from 450 to $550 \mathrm{~nm}$ with excitation at $390 \mathrm{~nm}(2.5 \mathrm{~nm}$ band width) on mixtures containing $80 \mu \mathrm{g}$ of sample protein in $1 \mathrm{~mL}$ of the appropriate buffer and increasing concentrations of ANS, added as very small volumes from 2 or $20 \mathrm{~m} M$ stock solutions in water. Binding curves were analyzed according to standard procedures (Bonomi et al., 1988; Pagliarini et al., 1990).

\section{RESULTS}

\section{MW of CMP is Independent of pH}

The effect of $\mathrm{pH}$ on the apparent MW of 4 different CMP products was analyzed by SEC at $\mathrm{pH} 8.0$ and $\mathrm{pH}$ 3.4 (Figure 1). Caseinomacropeptide from chymosinhydrolyzed $\kappa$-CN as well as commercial CMP products (Sigma and Arla; Figure 1, panels A to C) eluted at both $\mathrm{pH}$ values, as a single, broad peak with a mean MW of approximately $35 \mathrm{kDa}$.

The elution profile of pepsin-hydrolyzed $\kappa$-CN (Figure 1D) however, differed from that of the other 3 products. At $\mathrm{pH}$ 8.0, this preparation resolved into 4 peaks with 
pH 8.0

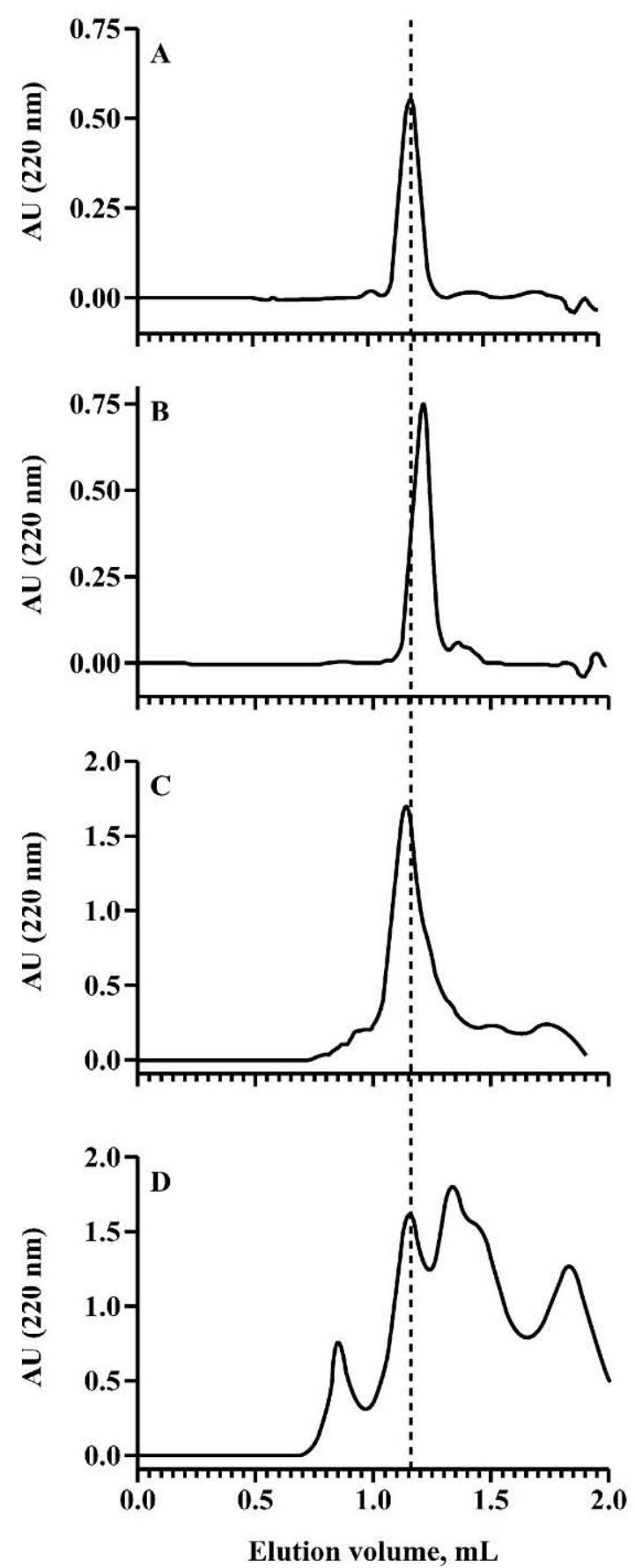

pH 3.4

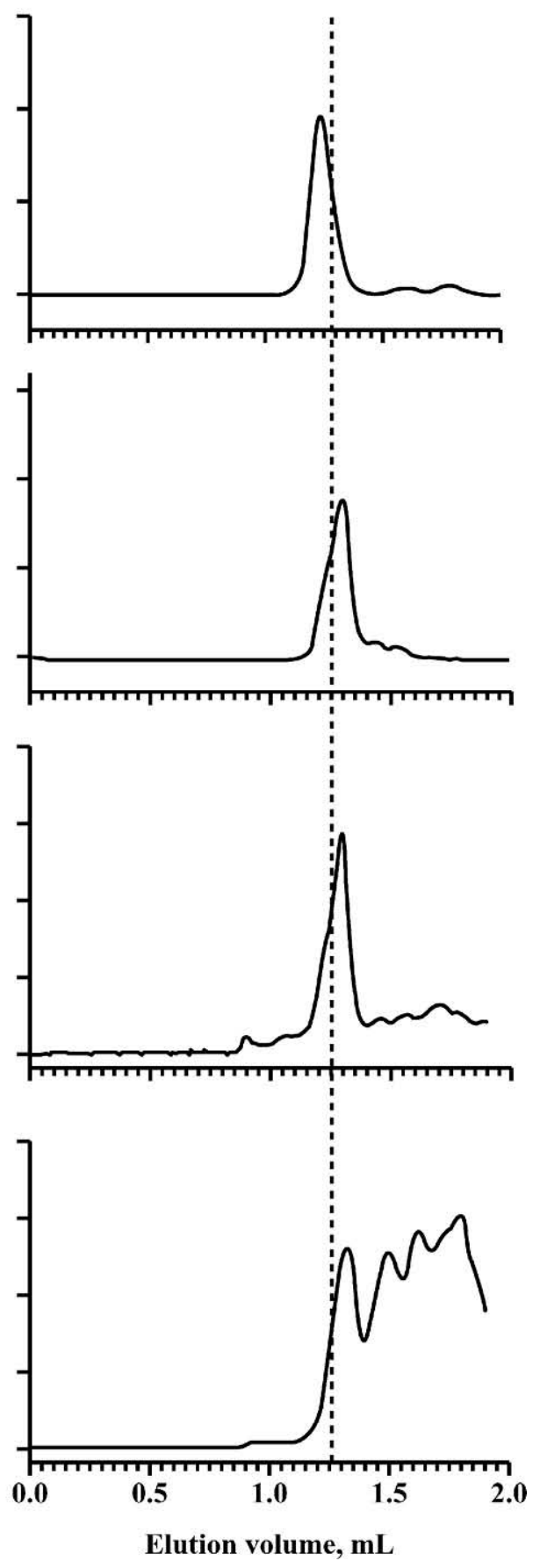

Figure 1. Elution profiles of caseinomacropeptide (CMP) after size-exclusion chromatography at pH 8.0 and 3.4. A) CMP from Sigma, B) CMP from Arla, C) chymosin-hydrolyzed (pH 6.6) $\kappa$-casein, D) pepsin-hydrolyzed (pH 2.5) $\kappa$-casein. Sample size = $25 \mu \mathrm{L}(3 \mathrm{mg} / \mathrm{mL}$ ); AU = absorbance units; vertical dashed line represents $\mathrm{MW}=35 \mathrm{kDa}$.

MW $>70,35,18$, and $9 \mathrm{kDa}$. The largest fraction was absent when the separation was carried out at $\mathrm{pH} 3.4$. The peak with MW $>70 \mathrm{kDa}$ had only little absorbance at $280 \mathrm{~nm}$; hence, it may represent a high-MW aggregate of CMP. At both $\mathrm{pH}$ values, a peak with $\mathrm{MW}<6$
$\mathrm{kDa}$ was observed, which might be related to para $\kappa$ $\mathrm{CN}$-derived peptides.

Given that CMP has a sequence-calculated mass of $6.707 \mathrm{kDa}$, our SEC data clearly illustrate that both at $\mathrm{pH} 8.0$ and 3.4, CMP migrates as a mixture of polymers 


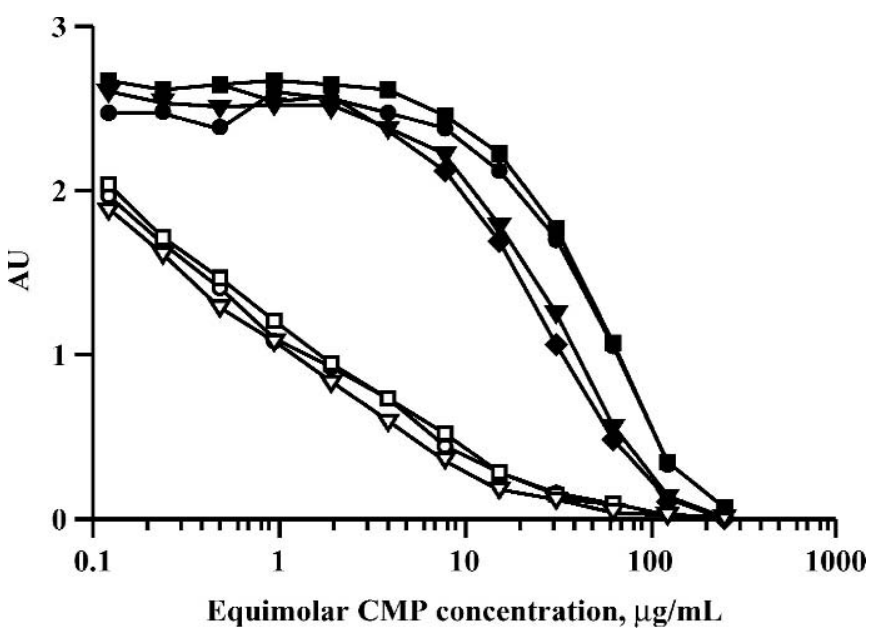

Figure 2. Inhibition curves from competitive ELISA. Plates were coated with $0.5 \mu \mathrm{g} / \mathrm{mL}$ CMP (Sigma) and incubated with anti-CMP antibody and CMP or $\kappa$-casein as competitor. $\mathbf{\square}=$ pepsin hydrolyzed $(\mathrm{pH} 2.5) \kappa$-casein, $\boldsymbol{\bullet}=$ chymosin hydrolyzed $(\mathrm{pH}$ 6.6) $\kappa$-casein, $\boldsymbol{\nabla}=$ CMP from Arla, = CMP from Sigma, $\square=$ pepsin-control, $O=$ chymosin-control, $\nabla=\kappa$-casein. $\mathrm{AU}=$ Absorbance units.

and that the apparent aggregation of CMP is not solely influenced by the actual $\mathrm{pH}$. In fact, incubation of CMP (Arla) in $0.1 \mathrm{M} \mathrm{HCl}$ at $80^{\circ} \mathrm{C}(1 \mathrm{~h})$ or at $\mathrm{pH} 3.4\left(4^{\circ} \mathrm{C}\right.$ at $20 \mathrm{~h}$ ) did not result in dissociation of CMP into lower MW forms (results not shown).

As the mean theoretical MW of CMP is approximately $7 \mathrm{kDa}$, the peaks observed in the SEC corresponding to 35,18 , and $9 \mathrm{kDa}$ may represent tetrameric, dimeric, and monomeric forms of CMP, respectively.

\section{Immunochemical Analyses of Enzymatic Hydrolysis Products}

The immunochemical reactivity of the 4 CMP products was compared in a competitive ELISA, based on inhibition of binding of monoclonal anti-CMP antibodies to immobilized CMP. The resulting inhibition curves (Figure 2), which are representative of curves obtained using 3 different monoclonal antibodies toward CMP, showed that hydrolyzed $\kappa$-CN (from either chymosin or pepsin hydrolysis), as well as both commercial CMP products, were equally efficient at inhibiting antibody binding, indicating immunochemically identical structures of all the CMP products.

The data in Figure 2 also provide evidence of a large difference in the inhibitory capacities of intact $\kappa$-CN vs. CMP, with a more than 10 -fold higher inhibitory concentration for CMP compared with intact $\kappa$-CN. In other words, CMP-specific antibodies recognize CMPspecific epitopes in intact $\kappa$-CN much better than in isolated (but heteropolymeric) CMP. These data also confirm that $\kappa$-CN was completely hydrolyzed by both enzymes as shown by the SEC tracings in Figure 1, panels $\mathrm{C}$ and $\mathrm{D}$. Intact $\kappa$-CN eluted in the void volume in separate SEC runs (results not shown).

\section{CMP is Present in SEC Peaks with MW Corresponding to 35,18 , and $9 \mathrm{kDa}$}

Sodium dodecyl sulfate-PAGE, competitive ELISA, protein sequencing, and MS were used to confirm that CMP was present in the SEC fractions corresponding to 35,18 , and $9 \mathrm{kDa}$ as collected from chymosin- and pepsin-hydrolyzed $\kappa$-CN. Elution profiles from a preparative column (Superdex 75 column; Hiload 26/60, AP Biotech) were similar to those obtained from the analytical column (Superdex 75 PC 3.2/30) presented in Figure 1.

Analysis of pepsin-hydrolyzed $\kappa-\mathrm{CN}$ ( $\mathrm{pH} 2.5$ ) by SDSPAGE, followed by silver-staining of the gels, showed protein bands of approximately $18 \mathrm{kDa}$ (lanes 1 to 4 , Figure $3 \mathrm{~B}$ ) in fractions corresponding to a MW of both $35 \mathrm{kDa}$ (fractions 1 to 3 , Figure $3 \mathrm{~A}$ ) and $18 \mathrm{kDa}$ (fraction 4, Figure 3A). The 9-kDa peak (fraction 5) contained protein bands with MW of 7,000 and lower (lane 5, Figure 3B). Caseinomacropeptide from Arla and Sigma, as well as chymosin-hydrolyzed $\kappa$-CN, were visible as a broad smear with somewhat resolved bands having $\mathrm{MW}$ around 35,18 , and $10 \mathrm{kDa}$ (lanes $\mathrm{C}_{\mathrm{A}}, \mathrm{C}_{\mathrm{S}}$, and $\mathrm{C}$, Figure $3 \mathrm{~B}$ ). A faint band at $7 \mathrm{kDa}$ is also visible in the Arla product (lane $\mathrm{C}_{\mathrm{A}}$, Figure $3 \mathrm{~B}$ ).

Caseinomacropeptide could be detected by competitive ELISA in the 35, 18, and $9 \mathrm{kDa}$ fractions (Figure $3 \mathrm{~A})$. It was not possible to detect any CMP in peaks with a MW lower than $9 \mathrm{kDa}$ (fractions 6 and 7) that are therefore likely to exclusively represent peptides derived from further degradation of either para $\kappa-\mathrm{CN}$ or CMP. Protein sequence analysis demonstrated that the main sequence in the 35,18 , and $9 \mathrm{kDa}$ fractions corresponded to the $\mathrm{N}$-terminal sequence of CMP (Table 1). Note that peptides originating from the $\mathrm{N}$-terminal region of $\kappa$-CN would not be detected by Edman degradation, as the pyroglutamic residue is impervious to this reaction. Up to 22 residues of the samples corresponding to the 18- and 9-kDa peaks were sequenced to confirm the CMP sequence. In the 9-kDa fraction, other peptides were also detected, with $\mathrm{N}$-terminals representing Ala138 and Ser80 of $\kappa$-CN, respectively.

Mass spectrometry analysis demonstrated that the main component in the CMP product from Arla was the monophosphorylated monomeric form of CMP (both genetic variants $\mathrm{A}$ and $\mathrm{B}$; data not shown). The monomeric form was also detected in the $35 \mathrm{kDa}$ SEC peaks of chymosin- and pepsin-hydrolyzed $\kappa$-CN (Table 1 , fraction 3). Moreover, MS detected a species with a 
$\mathbf{A}$

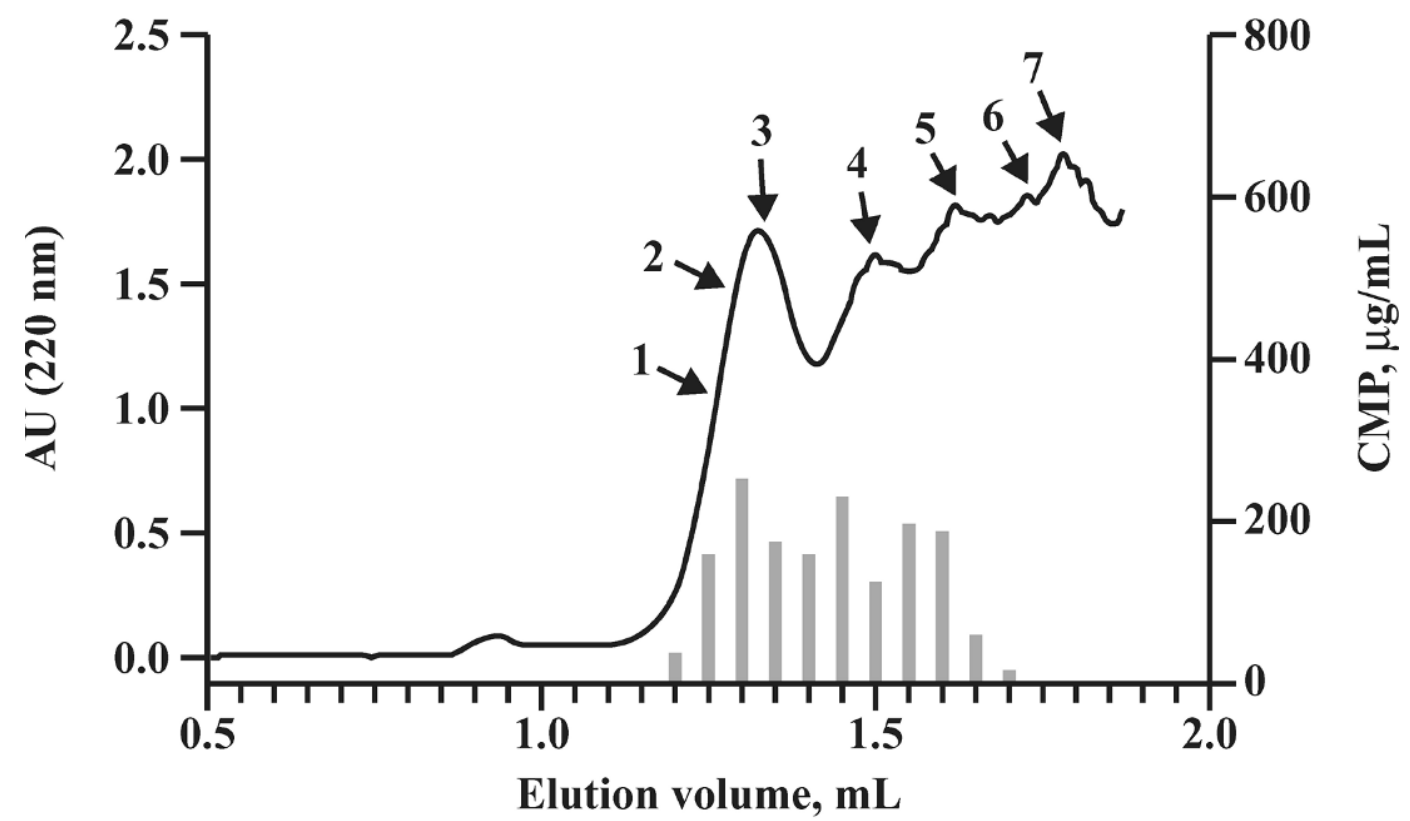

B

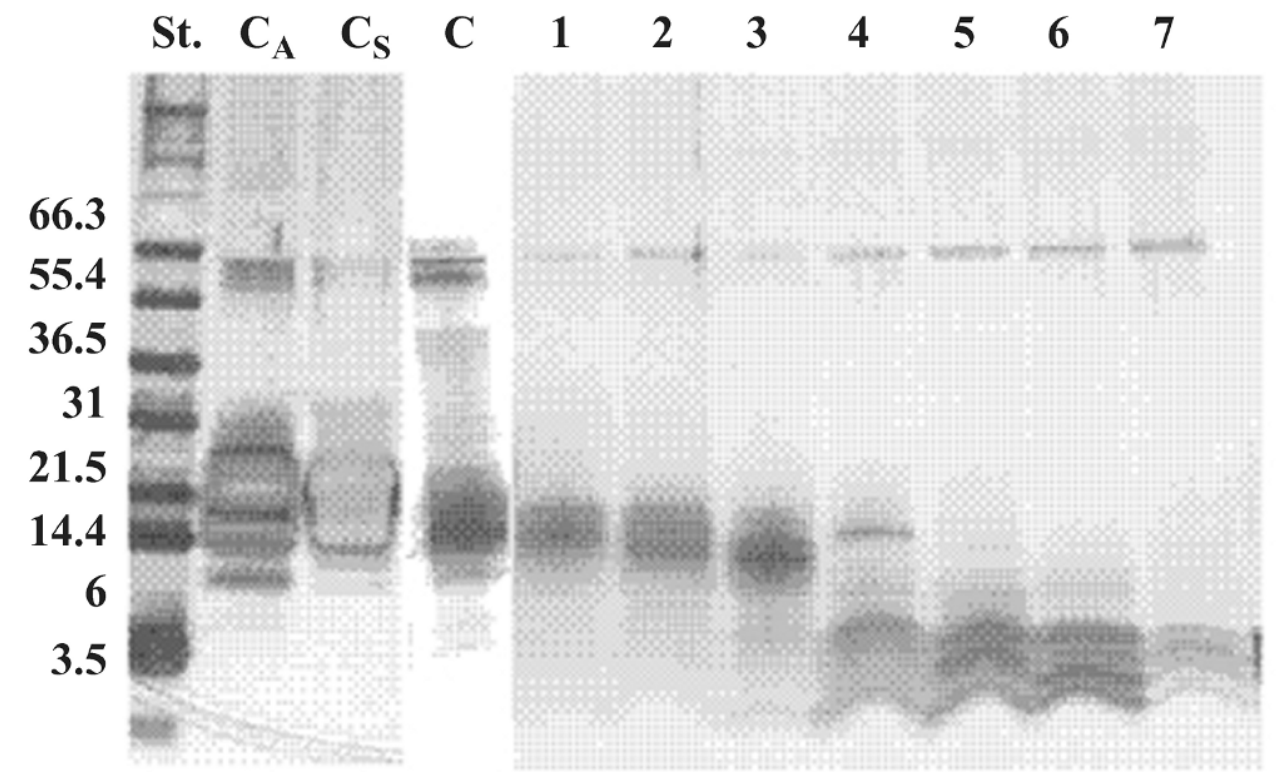

Figure 3. A) Elution profiles from size-exclusion chromatography (SEC) at $\mathrm{pH} 3.4$ of pepsin-hydrolyzed $\kappa$-casein. The numbers indicate collected fractions. Gray bars indicate CMP content in fractions $(\mu \mathrm{g} / \mathrm{mL})$ determined by ELISA. B) Silver-stained SDS-PAGE gels of fractions collected from SEC after pepsin-hydrolysis of $\kappa$-casein. $\mathrm{St}=$ Molecular weight standard, $\mathrm{C}_{\mathrm{A}}=\mathrm{CMP}$ from Arla; $\mathrm{C}_{\mathrm{S}}=\mathrm{CMP}$ from Sigma; $\mathrm{C}=$ chymosin-hydrolyzed $\kappa$-casein; lanes 1 to 7 = fractions 1 to 7 (as indicated by arrows in Figure 3A).

mass corresponding to that of the monomeric CMP in the 9-kDa SEC peak of pepsin-hydrolyzed $\kappa$-CN (Table 1 , fraction 5). Consistent with the results of SDS-PAGE, matrix-assisted laser desorption ionization time-of- flight MS analysis indicated the absence of covalently linked tetrameric CMP in the various SEC fractions.

The results described above demonstrate that CMP is present in the 35,18 , and $9 \mathrm{kDa}$ SEC peaks, thus 
Table 1. Characterization of fractions from size-exclusion chromatography.

\begin{tabular}{lllrl}
\hline $\begin{array}{l}\text { Fraction } \\
\text { no. }^{1}\end{array}$ & Peptide sequence $^{2}$ & Position in $\kappa$-casein & $\begin{array}{l}\text { MW, }{ }^{3} \\
\mathrm{kDa}\end{array}$ & $\mathrm{MW},{ }^{4} \mathrm{Da}$ \\
\hline 3 & MAI & Met106 & 35 & $6756,6788,6985,7151$ \\
4 & MAI & Met106 & 18 & $\mathrm{ND}^{5}$ \\
5 & MAI, AVE, SNT & Met106, Ala138, Ser80 & 9 & $3943,6783,9787$ \\
7 & VQV & Val162 & $<7$ & ND \\
\hline
\end{tabular}

${ }^{1}$ Size-exclusion chromatography fractions as shown in Figure 3A.

${ }^{2}$ Major species only.

${ }^{3}$ Mean apparent molecular weight (MW) determined by size-exclusion chromatography.

${ }^{4}$ Determined by mass spectrometry, major species only.

${ }^{5} \mathrm{ND}=$ Not determined.

indicating that CMP can exist as a tetramer, dimer, and monomer. The dimeric and monomeric forms of CMP were seen when $\kappa$-CN was cleaved by pepsin, but not with chymosin. A major difference in these enzymatic cleavages is the $\mathrm{pH}$ at which they were carried out: $\mathrm{pH} 2.5$ for pepsin-hydrolysis compared with $\mathrm{pH} 6.6$ for chymosin-hydrolysis.

\section{pH Influences Interactions Between CMP Units in $\kappa$-CN Molecules Before and During Hydrolysis}

A series of experiments were performed where the aim was to study the effect of $\mathrm{pH}$ on the association of $\mathrm{CMP}$ in the $\kappa$-CN molecule, focusing on the peptidepeptide interactions at the very moment in which CMP is released by enzymatic hydrolysis. For this purpose, the aggregation state of CMP products resulting from chymosin- or pepsin-hydrolysis of $\kappa-\mathrm{CN}$ at $\mathrm{pH} 2.5,3.4$, and 6.6 was investigated by SEC. In all experiments, $\kappa$-CN was incubated at $\mathrm{pH} 2.5$ before hydrolysis at different $\mathrm{pH}$ values.

Hydrolysis of $\kappa$-CN at $\mathrm{pH} 6.6$ with either pepsin or chymosin resulted in a CMP product that eluted as a single peak with a MW of $35 \mathrm{kDa}$ (Figure 4, panels A and B). However, when chymosin- or pepsin-hydrolysis was carried out at either $\mathrm{pH} 3.4$ or 2.5 , the resulting products also contained lower MW components (Figure 4, panels $\mathrm{A}$ and $\mathrm{B}$ ), including peaks corresponding to dimeric and monomeric CMP. Front peaks containing nonhydrolyzed $\kappa$-CN were seen for pepsin-hydrolysis of $\kappa$-CN at pH 3.4 and 6.6. Long-term (up to $24 \mathrm{~h}$ ) incubation of $\kappa-\mathrm{CN}$ at $\mathrm{pH} 2.5$ before hydrolysis did not affect the distribution of CMP product obtained by subsequent enzymatic hydrolysis (result not shown).

These results demonstrate that the $\mathrm{pH}$ at which proteolysis of $\kappa$-CN took place influenced the form and consequently the MW of the resulting CMP product. Thus, the CMP parts of $\kappa$-CN molecules appear to associate and dissociate depending on $\mathrm{pH}$, and the degree of association of the CMP molecules will depend on the state of aggregation of the $\kappa$-CN molecule at the time of hydrolysis.

\section{The Tetrameric Form of CMP is More Hydrophobic than the Dimeric and Monomeric Forms}

Given the absence of covalent bonds in CMP aggregates, and their insensitivity to $\mathrm{pH}$ in SEC separations, strong interaction through hydrophobic contacts can be hypothesized to hold together polymeric forms of CMP. The surface hydrophobicity of various CMP aggregates isolated by SEC were studied by measuring the binding of ANS, a hydrophobic fluorescent probe that preferably binds to hydrophobic surfaces of proteins (Matulis and Lovrien, 1998). Titration studies with ANS demonstrated that tetrameric forms of CMP from SEC fractions were significantly more hydrophobic than the dimeric and monomeric forms of CMP isolated by SEC (Figure 5).

Size-exclusion chromatography fractions containing monomeric CMP showed a limited number of surface hydrophobic sites (inferred from fluorescence values at saturating ANS (Iametti et al., 1996, 1998), and this parameter only increased slightly upon dimerization. However, tetrameric CMP forms isolated by SEC showed a 3-fold increase in the number of ANS-accessible surface hydrophobic sites relative to dimeric CMP, a behavior that has been associated with the establishment of new hydrophobic sites upon contact between specific protein regions (Iametti et al., 1998). Figure 5 also makes it clear that the establishment of these interprotein connections does not involve major structural rearrangements, as it does not modify the apparent affinity of the various forms of CMP for the probe, as indicated by the slopes of lines in the Scatchard plots (Figure 5C), reflecting the apparent $\mathrm{K}_{\mathrm{d}}$ for dissociation of the ANS-protein complex (Pagliarini et al., 1990; Iametti et al., 1996). 

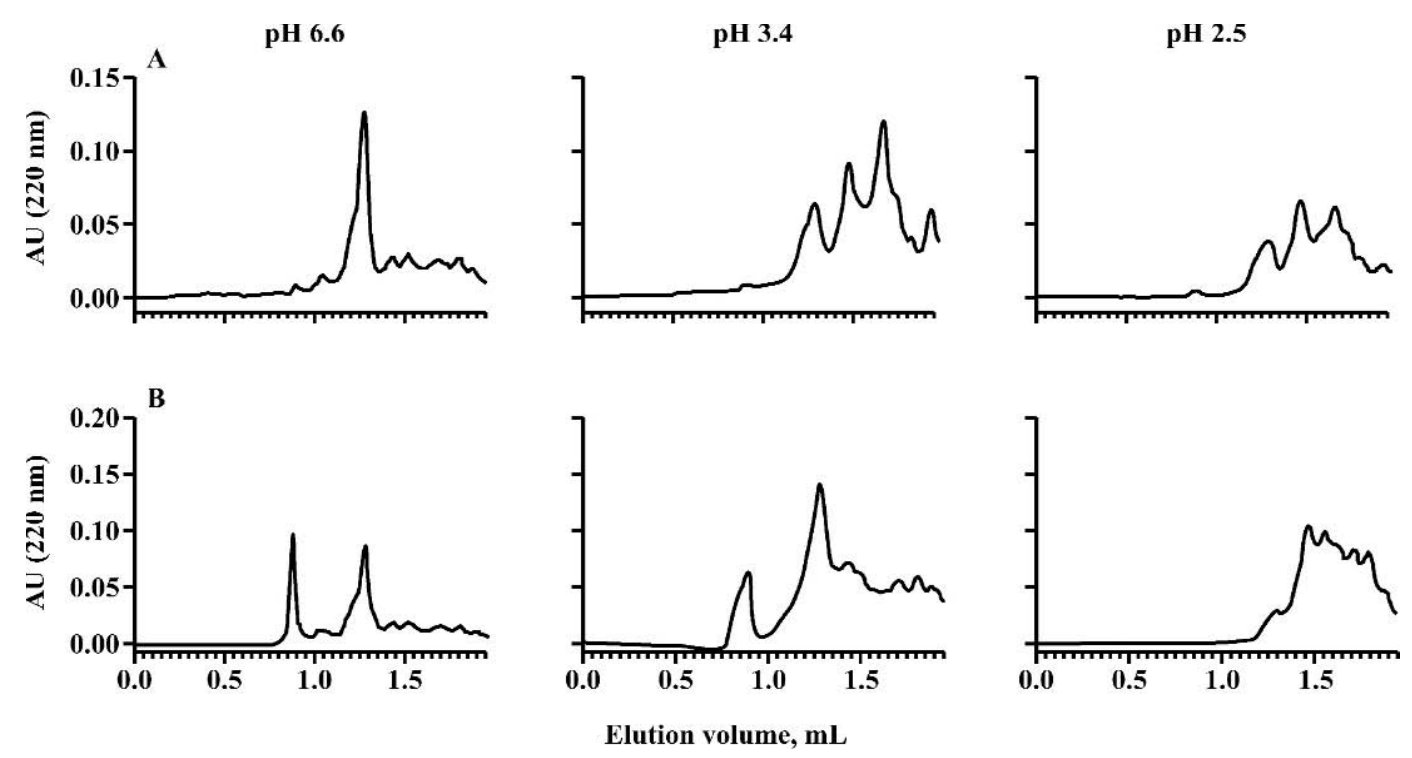

Figure 4. Effect of A) chymosin- and B) pepsin-hydrolysis of $\kappa$-casein at $\mathrm{pH} 6.6,3.4$, and 2.5. Elution profiles after size-exclusion chromatography at $\mathrm{pH} 3.4$ are illustrated [sample size $=25 \mathrm{~mL}(3 \mathrm{mg} / \mathrm{mL})]$.

\section{DISCUSSION}

The greater than theoretical MW often reported in the literature for CMP is thought to be caused by a large hydrodynamic volume or by association of monomers to form aggregates. The results presented in this study support the latter hypothesis. These aggregates do not associate and dissociate in a $\mathrm{pH}$-dependent manner. Moreover, $\mathrm{pH}$-dependent interactions between CMP molecules seem to take place within the $\kappa$-CN micelles, and we suggest that these interactions will influence the resulting CMP product arising from enzymatic cleavage. Overall, the results indicate that CMP units in $\kappa$-CN appear to associate reversibly depending on $\mathrm{pH}$, whereas free CMP monomers do not tend to associate once they have been formed.

In the present study, we investigated the effect of $\mathrm{pH}$ ( $\mathrm{pH} 3.4$ and 8.0) on the MW of 4 CMP products by SEC. We found that independently of $\mathrm{pH}, \mathrm{CMP}$ had a greater than expected MW although a lower MW form of CMP, corresponding to a monomeric form, was produced together with a dimeric form by pepsin- and chymosinhydrolysis of $\kappa$-CN at $\mathrm{pH} 2.5$. Competitive ELISA, protein sequencing, and MS confirmed that CMP was present in the peaks corresponding to dimeric and monomeric CMP forms. Secondary hydrolysis products, which have also been reported by Shammet et al. (1992), were identified in the monomeric peak. Although secondary hydrolysis products add to the complexity of the multipeak elution profiles, the results presented for pepsin hydrolysis at $\mathrm{pH} 2.5$ are in accordance with the presence of nonhydrolyzed monomeric CMP.
The formation of aggregates has been reported in a study similar to the current study (Nakano and Ozimek, 1998), in which it was concluded that CMP could aggregate to form trimers having a MW of $36 \mathrm{kDa}$. Different sized forms of CMP have also been reported in studies where ultrafiltration was used to isolate CMP. Aggregates of different sizes of CMP were found, the majority having a MW ranging from 30 to $50 \mathrm{kDa}$, but also some having a MW $>50 \mathrm{kDa}$ at $\mathrm{pH} 4.6$ (Kawasaki et al., 1993; Chu et al., 1996).

The lack of $\mathrm{pH}$-dependent change in MW of free CMP seen in the present study is in agreement with previous studies (Minkiewicz et al., 1996; Nakano and Ozimek, 1998) although Kawasaki et al. (1993) reported that a decrease in $\mathrm{pH}$ resulted in a decrease in MW. This discrepancy in results could be caused by different production methods of CMP or $\mathrm{pH}$-dependent interaction with SEC column material.

Sodium dodecyl sulfate-PAGE analysis revealed that CMP in both the tetrameric and dimeric fractions appeared as an $18-\mathrm{kDa}$ protein band. Thus, although the tetrameric CMP product appears to be resistant to changes in $\mathrm{pH}$ (as described above) it can be reduced to $18 \mathrm{kDa}$ by SDS-PAGE. As the dimeric form appears to be resistant to SDS-PAGE, we suggest that dimeric CMP is composed of 2 tightly associated CMP monomers. In the monomeric fraction (Figure 3B, lane 5), there is a protein band with a MW of approximately 7 $\mathrm{kDa}$, which may represent monomeric CMP. This protein band is not present in fractions 6 and 7, which elute at volumes corresponding to a MW lower than 9 


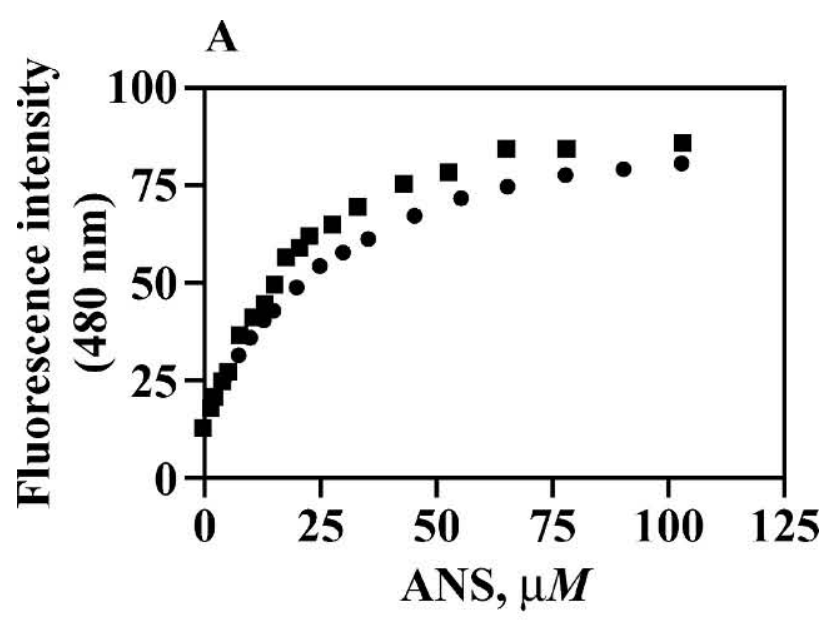

B
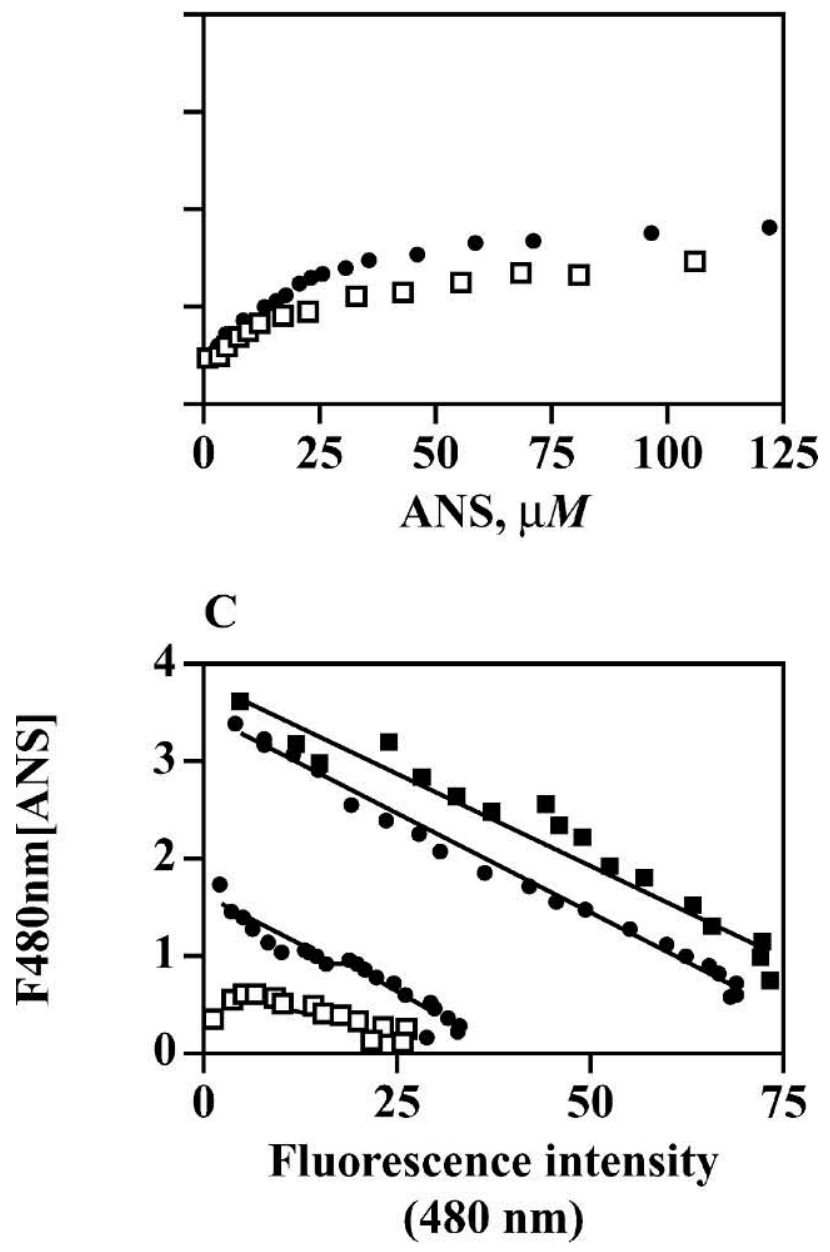

Figure 5. 1-Anilinonaphthalene-8-sulfonic acid (ANS) binding curves for A) tetrameric, and B) dimeric and monomeric fractions of caseinomacropeptide (CMP) from chymosin- and pepsin-hydrolyzed $\kappa$-casein; C) Scatchard plot of ANS binding to fractions of CMP: $\mathbf{\square}=$ chymosin-hydrolyzed $\kappa$-casein (tetrameric fraction); 0 pepsin-hydrolyzed $\kappa$-casein (tetrameric fraction); $\boldsymbol{\nabla}=$ CMP from Arla; $\bullet=$ pepsin-hydrolyzed $\kappa$-casein (dimeric fraction); $\square=$ pepsin-hydrolyzed $\kappa$-casein (monomeric fraction).
$\mathrm{kDa}$. Our studies showed that silver-stained gels revealed more lower MW proteins than did Coomassiestained gels (results not shown). In relation to this, most previous studies report only the aggregated form of CMP (Coolbear et al., 1996; Chow and Harper, 2001; Nakano et al., 2002), which may be due to the use of Coomassie staining, which requires higher protein concentrations than silver staining.

The present studies on the effect of $\mathrm{pH}$ at the moment of $\kappa$-CN hydrolysis, demonstrated that the MW of the resulting CMP product was influenced by $\mathrm{pH}$. Hydrolysis of $\kappa$-CN by either chymosin or pepsin at $\mathrm{pH} 6.6$ (whether $\kappa$-CN had been preincubated at $\mathrm{pH} 2.5$ or not) resulted in only the tetrameric form of CMP. Hydrolysis of $\kappa$-CN by both enzymes at $\mathrm{pH} 2.5$ or 3.4, however, produced elution profiles consisting of peaks with MW corresponding to dimeric and monomeric forms of CMP as well as the tetrameric form. We propose that $\mathrm{pH}$ may induce a change in conformation of $\kappa$-CN that affects association of CMP units between adjacent $\kappa$-CN molecules and that this change is reversible as long as CMP is still a part of $\kappa$-CN.

The overall structure of $\kappa$-CN has been shown to be flexible (Griffin and Roberts, 1985), and a decrease in $\mathrm{pH}$ can cause slight changes in conformation such as increased $\alpha$-helical content (Plowman et al., 1997). $\kappa$ Casein molecules form micelles (Farrell et al., 1996), in which $\kappa$-CN molecules are orientated with their hydrophobic regions (para- $\kappa-\mathrm{CN}$ segment) forming the core, and the hydrophilic CMP segment projecting outwards (Vreeman et al., 1981). Based on our findings, we suggest that the $\mathrm{pH}$-induced change in the conformation of $\kappa$-CN in turn affects the association or interaction of CMP units between adjacent $\kappa$-CN molecules. A lower $\mathrm{pH}$ may result in a structure where CMP molecules are less closely associated, perhaps due to conformation changes in the para- $\kappa$ - $\mathrm{CN}$ part, whereas at $\mathrm{pH}$ $6.6, \kappa$-CN exists as a more tightly bound aggregate, resulting in a closer association of CMP units.

In support of the above, a recent study by Kim et al. (2005) demonstrated that in SDS-PAGE, recombinant human CMP had mobility corresponding to a MW of 7 $\mathrm{kDa}$. In contrast, the mobility of natural bovine CMP corresponded to a MW of $20 \mathrm{kDa}$.

In this study, analysis of surface properties of CMP by ANS-binding experiments revealed that CMP (from Arla) and the tetrameric fraction from SEC had greater hydrophobicity than did the monomeric and dimeric fractions. These results indicate that aggregation of monomers having a relatively small hydrophobic surface form a tetrameric structure with a hydrophobic patch. As increased hydrophobicity will decrease the binding of water molecules to the protein aggregate, these results imply that hydration is not the cause of 
the increased MW of CMP as previously suggested by Minkiewicz et al. (1996).

Regarding previous proposals that carbohydrate chains are involved in the greater than expected MW, we found that incubation under acidic conditions, which would cause removal of sialic acid (Schauer, 1982), did not influence the elution pattern of CMP in SEC (results not shown). Similar results have been published (Nakano and Ozimek, 1998, 2000). Furthermore, as about $40 \%$ of CMP is glycosylated (Vreeman et al., 1986), it is unlikely that the increased MW is caused by carbohydrate attachments alone.

The results presented in this study support the hypothesis that the increased MW determined for CMP is caused by aggregation of monomeric CMP forms, and is not due to attached carbohydrate chains. It should be noted however, that although the MW observed in SEC correspond well with the suggested presence of monomeric, dimeric, and tetrameric forms of CMP, it is possible that changes in the apparent MW are caused by binding of hydrophobic peptides, derived from para $\kappa$ CN under acidic conditions, to CMP. Such peptides bound to CMP would ultimately cause a decrease in apparent MW and decrease the ANS reaction. Further studies need to be done to clarify this hypothesis.

\section{CONCLUSIONS}

This study demonstrated that the greater than theoretical apparent MW of CMP is due to aggregation of monomeric CMP. We propose that CMP aggregates consist of 4 CMP molecules and that these aggregates, once formed, are resistant to changes in $\mathrm{pH}$. We suggest that the formation and conformation of the CMP aggregates are influenced by properties of the CMP units in $\kappa$-CN, and that CMP units attached to $\kappa$-CN are reversibly influenced by $\mathrm{pH}$. These findings are important for gaining a better understanding of the properties of CMP, which is crucial for optimizing methods of isolation of this peptide in such a way that the bioactive properties are preserved.

\section{ACKNOWLEDGMENTS}

The technical assistance of Nina Milora is greatly appreciated. The authors also thank Anne Blicher for performing the amino acid analyses and protein sequencing. The study was supported by The Danish Program for Advanced Food Technology (FØTEK), The Danish Dairy Research Foundation, and Centre for Advanced Food Studies (LMC), Copenhagen, Denmark.

\section{REFERENCES}

Abd El-Salam, M. H., S. El-Shibiny, and W. Buchheim. 1996. Characteristics and potential uses of the casein macropeptide. Int. Dairy J. 6:327-341.
Barkholt, V., and A. L. Jensen. 1989. Amino acid analysis: Determination of cysteine plus half-cysteine in proteins after hydrochloric acid hydrolysis with a disulfide compound as additive. Anal. Biochem. 177:318-322.

Blum, H., H. Beier, and H. J. Gross. 1987. Improved silver staining of plant proteins, RNA and DNA in polyacrylamide gels. Electrophoresis 8:93-99.

Bonomi, F., S. Iametti, E. Pagliarini, and C. Peri. 1988. A spectrofluorimetric approach to the estimation of the surface hydrophobicity modifications in milk proteins upon thermal treatment. Milchwissenschaft 43:281-285.

Brody, E. P. 2000. Biological activities of bovine glycomacropeptide. Br. J. Nutr. 84(Suppl. 1):S39-S46.

Chow, D. L., and W. J. Harper. 2001. Selected characteristics of casein glycomacropeptide from different sources. Milchwissenschaft 56:370-373.

Chu, L., A. Macleod, and L. Ozimek. 1996. Isolation of glycomacropeptide from sodium caseinate hydrolysate solution by ultrafiltration. Milchwissenschaft 51:303-306.

Coolbear, K. P., D. F. Elgar, T. Coolbear, and J. S. Ayers. 1996. Comparative study of methods for the isolation and purification of bovine kappa-casein and its hydrolysis by chymosin. J. Dairy Res. 63:61-71.

Delfour, A., J. Jolles, C. Alais, and P. Jolles. 1965. Caseino-glycopeptides: Characterization of a methionine residue and of the $\mathrm{N}$ terminal sequence. Biochem. Biophys. Res. Commun. 19:452-455.

Farrell, H. M., Jr., P. H. Cooke, G. King, P. D. Hoagland, M. L. Groves, T. F. Kumosinski, and B. Chu. 1996. Particle sizes of casein submicelles and purified $\kappa$-casein: Comparisons of dynamic light scattering and electron microscopy with predictive threedimensional molecular models. ACS Symposium Series 650:6181.

Farrell, H. M., Jr., R. Jimenez-Flores, G. T. Bleck, E. M. Brown, J. E. Butler, L. K. Creamer, C. L. Hicks, C. M. Hollar, K. F. NgKwai-Hang, and H. E. Swaisgood. 2004. Nomenclature of the proteins of cows' milk-Sixth revision. J. Dairy Sci. 87:1641-1674.

Griffin, M. C., and G. C. Roberts. 1985. A 1H-n.m.r. study of casein micelles. Biochem. J. 228:273-276.

Holst, H. H., and D. E. W. Chatterton. 2002. A process for preparing a kappa-caseino glycomacropeptide or a derivative thereof. Eur. Pat. No. 1037537 B1. Assignee: Arla Foods Amba, Viby, Denmark.

Iametti, S., B. De Gregori, G. Vecchio, and F. Bonomi. 1996. Modifications occur at different structural levels during the heat denaturation of beta-lactoglobulin. Eur. J. Biochem. 237:106-112.

Iametti, S., L. Scaglioni, S. Mazzini, G. Vecchio, and F. Bonomi. 1998. Structural features and reversible association of different quaternary structures of beta-lactoglobulin. J. Agric. Food Chem. 46:2159-2166.

Jolles, J., F. Schoentgen, C. Alais, and P. Jolles. 1972. Studies on the primary structure of cow kappa-casein: The primary sequence of cow para-kappa-casein. Chimia (Aarau) 26:645-646.

Kawasaki, Y., H. Kawakami, M. Tanimoto, S. Dosako, A. Tomizawa, M. Kotake, and I. Nakajima. 1993. pH-Dependent molecular weight changes of kappa-casein glycomacropeptide and its preparation by ultrafiltration. Milchwissenschaft 48:191-196.

Kim, Y. J., S. Park, Y. K. Oh, W. Kang, H. S. Kim, and E. Y. Lee. 2005. Purification and characterization of human caseinomacropeptide produced by a recombinant Saccharomyces cerevisiae. Prot. Expr. Purif. 41:441-446.

Matulis, D., and R. Lovrien. 1998. 1-Anilino-8-naphthalene sulfonate anion-protein binding depends primarily on ion pair formation. Biophys. J. 74:422-429.

Minkiewicz, P., C. J. Slangen, F. M. Lagerwerf, J. Haverkamp, H. S. Rollema, and S. Visser. 1996. Reversed-phase high-performance liquid chromatographic separation of bovine kappa-casein macropeptide and characterization of isolated fractions. J. Chromatogr. 743:123-135.

Nakano, T., and L. Ozimek. 1998. Gel chromatography of glycomacropeptide (GMP) from sweet whey on Sephacryl S-200 at different pH's and on Sephadex G-75 in 6M guanidine hydrochloride. Milchwissenschaft 53:629-633. 
Nakano, T., and L. Ozimek. 2000. Purification of glycomacropeptide from dialyzed and non-dialyzed sweet whey by anion-exchange chromatography at different $\mathrm{pH}$ values. Biotechnol. Lett. 22:1081-1086.

Nakano, T., E. R. Silva-Hernandez, N. Ikawa, and L. Ozimek. 2002. Purification of kappa-casien glycomacropeptide from sweet whey with undetectable level of phenylalanine. Biotechnol. Prog. 18:409-412.

Pagliarini, E., S. Iametti, C. Peri, and F. Bonomi. 1990. An analytical approach to the evaluation of heat damage in commercial milks. J. Dairy Sci. 73:41-44.

Plowman, J. E., L. K. Creamer, M. J. Liddell, and J. J. Cross. 1997. Solution conformation of a peptide corresponding to bovine kappacasein B residues 130-153 by circular dichroism spectroscopy and 1H-nuclear magnetic resonance spectroscopy. J. Dairy Res. 64:377-397.

Schagger, H., and G. von Jagow. 1987. Tricine-sodium dodecyl sulfatepolyacrylamide gel electrophoresis for the separation of proteins in the range from 1 to $100 \mathrm{kDa}$. Anal. Biochem. 166:368-379.

Schauer, R. 1982. Chemistry, metabolism, and biological functions of sialic acids. Adv. Carbohydr. Chem. Biochem. 40:231-234.
Shammet, K. M., D. J. McMahon, and R. J. Brown. 1992. Characteristics of macropeptide fraction isolated from whole casein and purified k-casein. Milchwissenschaft 47:615-619.

Tanimoto, M., Y. Kawasaki, S. Dosako, K. Ahiko, and I. Nakajima. 1992. Large-scale preparation of kappa-casein glycomacropeptide from rennet casein whey. Biosci. Biotechnol. Biochem. 56:140141.

Vreeman, H. J., J. A. Brinkhuis, and C. A. van der Spek. 1981. Some association properties of bovine SH-kappa-casein. Biophys. Chem. 14:185-193.

Vreeman, H. J., S. Visser, C. J. Slangen, and J. A. Van Riel. 1986. Characterization of bovine kappa-casein fractions and the kinetics of chymosin-induced macropeptide release from carbohydratefree and carbohydrate-containing fractions determined by highperformance gel-permeation chromatography. Biochem. J. 240:87-97.

Wang, T., and J. A. Lucey. 2003. Use of multi-angle laser light scattering and size-exclusion chromatography to characterize the molecular weight and types of aggregates present in commercial whey protein products. J. Dairy Sci. 86:3090-3101. 